\title{
El Almanaque Americano, la viruela en Santiago en 1872 y los lazaretos
}

\author{
Enrique Laval \\ The American Almanac, smallpox in Santiago in 1872 \\ and the isolations hospitals
}

Due to the smallpox epidemic in Santiago in 1872, a Commission or Central Board of isolation hospitals was created. These institutions were endowed with the necessary personnel to receive and assist the sick, highlighting the work of medical students, interns at these hospitals. The total number of patients treated in the infirmaries of Santiago reached 6,782, with a fatality rate of 3,073 (45.3\%).

Key words: Smallpox, epidmie, isolations hospitals.

Palabras clave: Viruela en Santiago, epidemia de 1872, lazaretos.

\section{Introducción}

$\mathrm{S}$ egún el Diccionario de la Lengua Española, almanaque es "el registro o catálogo que comprende todos los días del año, distribuidos por meses, con datos astronómicos como salidas y ocasos del sol, su entrada en cada signo del zodíaco, principio de las estaciones, fases de la luna, etc. y muchas otras noticias y épocas relativas a los actos religiosos y civiles" .

Tengo en mi poder el Almanaque Americano de 1873, que corresponde al año primero de su edición, 1872, impreso en la Imprenta Nacional, calle de la Moneda $\mathrm{N}^{\circ}$ 46, Santiago de Chile, distribuido por la Librería Central de don Augusto Raymond.

Dice el editor del Almanaque, "en cada uno de los años siguientes esperamos presentar datos estadísticos sobre la población, la instrucción pública, la agricultura, la industria y el comercio e iremos reuniendo noticias que no son siempre fáciles de encontrar a mano y nuestra publicación llegará a ser una especie de archivo, útil a toda clase de personas".

Llama la atención lo relatado latamente a partir del día 12 de junio de 1872 referente a los lazaretos para variolosos de Santiago, con una abundante información, que casi supera cualquier materia sobre el tema, posible de encontrar en otras publicaciones nacionales ${ }^{2-4}$.

\section{Constitución y funcionamiento de la Junta Central de Lazaretos}

El día mencionado se nombró una Comisión o Junta Central de Lazaretos, integrada por monseñor Ignacio
Víctor Eyzaguirre, don José Joaquín Aguirre, don José Manuel Guzmán, don Valentín Marcoleta, don Vicente Izquierdo, don Matías Ovalle y don Manuel Arriarán, como secretario, para combatir la epidemia de viruela que asolaba a Santiago en 1872. En ella había un solo médico, el doctor José Joaquín Aguirre. Los primeros pasos de

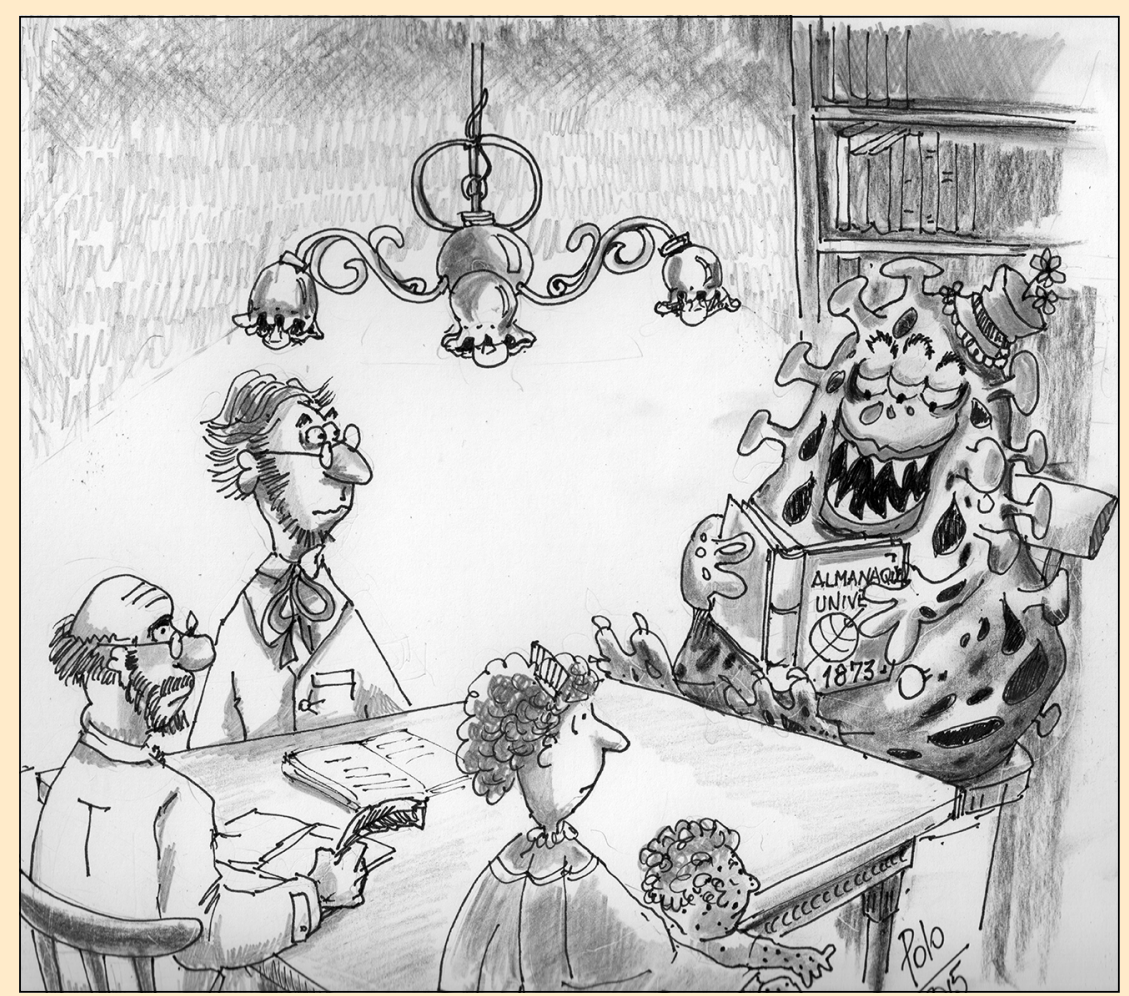

Pontificia Universidad Católica de Chile.

Facultad de Medicina.

Programa de Estudios Médicos

Humanísticos.

Recibido: 21 de abril de 2014

Correspondencia a:

Enrique Laval Román revinf@sochinf.cl 
la Junta fueron establecer, cuanto antes, lazaretos, para recibir a los atacados por la epidemia, que eran rechazados día a día, en la puerta de los hospitales en número que consternaba ${ }^{2}$.

En el Diccionario de la Lengua Española, se anota como primera acepción para lazareto, "hospital o lugar fuera de poblado, que se destina para hacer la cuarentena, a los que vienen de parajes infestados o sospechosos de enfermedad contagiosa. Como segunda acepción, "hospital de leprosos"'.

Dos días después que comenzó a funcionar la Junta, el 14 de junio, ya se abrió el lazareto San Rafael, en el barrio Yungay, con capacidad para recibir setenta enfermos. El día 17 quedó en estado de recibir internos variolosos, el de la Pía Unión, en el barrio de la Chimba, también con igual número. Pocos días después se le anexó otro departamento para niños, que por su tierna edad y algunos en período de lactancia, tenían que concurrir con sus propias madres. El 21 del mismo mes, empezó a funcionar el lazareto del Arenal en el mismo barrio, apto para 150 enfermos, con una rapidez vertiginosa, ya que en ocho días se adecuó para hospital, un local que antes era una ramada de matanza, con gran extensión de tabiques y edificios anexos para varias oficinas. Cuatro días más tarde inició sus funciones el de San Vicente de Paul en Yungay para recibir hasta 86 pacientes, además de un departamento que se instaló con la "decencia y comodidad" posibles para estudiantes de provincias, que no teniendo a sus familiares en Santiago, se encontraban en situación crítica. El 8 de julio quedó instalado el lazareto de San Pablo, en la calle de ese nombre, en un edificio magnífico proporcionado por la Municipalidad. Podía recibir hasta 350 enfermos y fue el que quedó en mejores condiciones.

Finalmente, el cuartel de Artillería, que el Gobierno entregó a la Junta para convertirlo en lazareto, se arregló para acoger hasta 300 enfermos; por fortuna, la declinación de la epidemia no hizo necesaria su ocupación.

Tan luego como el desahogo de los lazaretos lo permitió, se desocupó el de la Maestranza, que por el mucho tiempo que estaba en servicio se encontraba en malas condiciones higiénicas, con notable perjuicio para los enfermos. Se le restauró haciéndole desaparecer sus malas condiciones, sirviendo para trasladar allí al de la Pía Unión, cuyo local era el menos adecuado por su poca extensión y falta de otras condiciones indispensables. Aunque no corría a su cargo, la Junta también auxilió eficazmente al lazareto del Salvador y a los que se establecieron en Talagante y San Francisco de El Monte.

\section{Personal y equipamiento de los lazaretos}

Cada lazareto estaba dotado de un Administrador, a excepción del de San Pablo, que por su gran tamaño tenía dos; de uno o varios capellanes según el número de hospitalizados; de un médico para cada cincuenta enfermos; de un practicante, alumno de la Escuela de Medicina, para cada quince y del número de mozos de sala, mayordomos, cocineros, lavanderas y sirvientes de patio que las necesidades exigían.

Además, según el número de enfermos, poseían una o dos boticas, que eran servidas por alumnos de medicina, actuando de farmacéuticos. Se prestó atención muy preferente a la estadística médica, estableciéndose un registro a cargo de un alumno de medicina en que anotaba todas las circunstancias especiales de los enfermos que pudieran interesar a la ciencia.

Había también un servicio de socorros a domicilio para enfermos que, por motivos especiales, no podían concurrir a los lazaretos. No menos de mil personas se atendieron así, con asistencia médica, medicinas y "cuarenta centavos diarios por persona para alimentación”. Los estudiantes de medicina se constituyeron en internos de los lazaretos, desde su apertura hasta su completa liquidación.

La Comisión auxilió eficazmente a la Junta de Vacuna en sus trabajos, proporcionándole fondos para hacer frente a los gastos extraordinarios que significó la propagación de la vacuna, estableciendo servicios, con este objeto, en todas las subdelegaciones del departamento y poniendo a su disposición alumnos de la escuela de medicina. Se dedicó una pequeña parte de los fondos recogidos para la extinción de la viruela, para el aseo y desinfección de algunos barrios de la ciudad; lo cual por las circunstancias tan apremiantes, no podía hacerse según la práctica ordinaria.

La Junta dispuso de las cantidades siguientes:

- Por asignación fiscal $\$ 30.000$

- Por erogaciones particulares $\$ 30.000,26$

- De la Municipalidad y pueblo de Buenos Aires

- Del gobierno del Perú

$\$ 10.000$

Total

$\$ 90.265,26$

Se invirtió la suma de $\$ 61.192,11$ en los distintos lazaretos, quedando un saldo de $\$ 29.073,15$ en poder del señor Intendente de Santiago, don Benjamín Vicuña Mackenna.

Vale la pena señalar la contribución argentina y peruana a la campaña de vacunación antivariólica y al equipamiento de los lazaretos.

Antes de su disolución, la Junta acordó dar a nombre del vecindario de Santiago, a los administradores, capellanes, médicos, estudiantes de medicina y otras personas que habían desempeñado importantes funciones en la lucha contra la epidemia, una medalla conmemorativa $\mathrm{y}$ un diploma de honor, como testimonio del mérito que contrajeron con sus caritativos y a veces heroicos servicios. La ceremonia tuvo lugar en el local del Mercado Central el 25 de octubre de 1872.

Se destacó a los miembros de la Junta señores Eyzagui- 
rre y Ovalle y no se distinguió el nombre del Intendente de la Provincia, don Benjamín Vicuña Mackenna, quien no solo se comportó como un funcionario celoso, sino que también contrajo la viruela debido a sus frecuentes visitas a los lazaretos; pero este olvido acrisola sus méritos: no recordamos que en el Evangelio se hable de diplomas ni de medallas de honor ${ }^{2}$.

El total de enfermos de viruela internado en los lazaretos de Santiago, con motivo de la epidemia de 1872, alcanzó a 6.782, con una letalidad de 3.073 (45,3\%), ignorándose las cifras de los atendidos en sus domicilios ${ }^{4}$.

\section{Resumen}

Con motivo de la epidemia de viruela en Santiago en 1872, se constituyó una Comisión o Junta Central de Lazaretos, que se preocupó de recibir y asistir allí a los enfermos, dotados del personal necesario, destacándose la labor que prestaron los estudiantes de medicina, quienes se transformaron en internos de dichos nosocomios. El total de enfermos atendidos en los lazaretos de Santiago alcanzó a 6.782, con una letalidad de 3.073 (45,3\%).

\section{Referencias bibliográficas}

1.- Diccionario de la Lengua Española. 1970. Sobre Almanaque y lazareto. Definiciones.

2.- Almanaque Americano. 1873. (1er. $\mathrm{n}^{\circ}$ 1872). Sobre la epidemia de viruela en Santiago en 1872 y los lazaretos.

3.- Armstrong T. Elogio del doctor Tomás Armstrong. Apuntes sobre la epidemia de viruela en Valparaíso. 1872-73. AUCH 1873. Pág 705-10.

4.- Contardo M J. Causas de la propagación de la viruela en Chile y de la excesiva mortandad que producen sus epidemias en Santiago. AUCH 1877. Pág. 443-61. 